DOI 10.37882/2223-2982.2021.01.10

\title{
ПРОДОЛЖИТЕЛЬНОСТЬ ЖИЗНИ И СРЕДНИЙ ВОЗРАСТ КРЕСТЬЯНСКОГО НАСЕЛЕНИЯ МОРДОВСКОГО КРАЯ ВО ВТОРОЙ ПОЛОВИНЕ ХVIII ВЕКА ПО МАТЕРИАЛАМ КРАСНОСЛОБОДСКОГО УЕЗДА ШАЦКОЙ ПРОВИНЦИИ ВОРОНЕЖСКОЙ ГУБЕРНИИ
}

\begin{abstract}
LIFE EXPECTANCY AND AVERAGE AGE ON THE TERRITORY OF THE MORDOVIAN TERRITORY IN THE SECOND HALF OF THE XVIII CENTURY BASED ON THE MATERIALS OF KRASNOSLOBODSKY UYEZD SHATSKY PROVINCE VORONEZH PROVINCE
\end{abstract}

\section{Efimkin}

Summary: The purpose of the work is to analyze the development of the peasant household in the Mordovian region in the second half of the XVIII century and indicate their relationship with life expectancy on the example of the Krasnoslobodsky district of the Shatsky province of the Voronezh province.

Method. The methodological potential includes: a comparative historical method, the use of which makes it possible to show a comparative analysis of the development of various families and localities; a statistical method, the significance of which is obvious for analyzing data related to changes in the peasant family over the period under study.

Result. The study showed that at the beginning of the second half of the XVIII century on the territory of the modern Republic of Mordovia, the average life expectancy was 26.24 years, which was close to the indicators that were shown in General on the territory of the Russian Empire. Of course, it is worth noting that when considering the declining population over 18 years of age, the average age will increase to 37.82 years.

Conclusions. It was noted that persons under the age of 18 were slightly more than $40 \%$. This trend could not but affect the development of the peasant family and the peasant household, since just over $40 \%$ of men could reach labor maturity and thus continue to develop not only their own economy, but also the country as a whole.

Keywords: peasant family, age, average age, life expectancy, taxable population.

\author{
Ефимкин Денис Геннадьевич \\ Аспирант, НИИ Гуманитарных наук \\ при правительстве РМ, г. Саранск \\ efimkin.denis@mail.ru
}

Аннотация:Цель работы - провести анализ развития крестьянского домохозяйства Мордовского края во второй половине XVIII века и указать и их взаимосвязь с продолжительностью жизни на примере во Краснослободского уезда Шацкой провинции Воронежской губернии.

Метод. Методологический потенциал включает: сравнительно исторический метод, применение которого позволяет показать сравнительный анализ развития различных семей и населенных пунктов; статистический метод, значимость которого очевидна для анализа данных, связанных изменениями в крестьянской семье на протяжение исследуемого периода.

Результат. Исследование показало, что в начале второй половины XVIII века на территории современной Республики Мордовия средняя продолжительность жизни составила - 26,24 года, что было приближено к показателям, которые были показаны в целом на территории Российской империи. Конечно, стоит отметить, что при рассмотрение мужского населения старше 18 лет, средний возраст увеличится уже до 37,82 года.

Выводы. Была отмечено, что лиц, не достигших 18 лет - было чуть больше $40 \%$. Данная тенденция не могла не повлиять на тенденцию развития крестьянской семьи и крестьянского домохозяйства, так как чуть более $40 \%$ лиц мужского пола могло достигнуть трудовой зрелости и тем сам продолжить развитие не только своего хозяйства, но и страны в целом.

Ключевые слова: крестьянская семья, возраст, средний возраст, продолжительность жизни, податное население.
B опрос изучения крестьянского населения во второй половине XVIII века широко не изучался. Служивые люди, которые занимались переписью населения не занималась анализом продолжительности жизни или среднего возраста, а современные исследователи занимались лишь поверхностным изучением в связи с от- сутствием доступа к материалам ревизий. Хотя в фондах архивов есть материалы такие как переписные книги, которые заполнялись служителями церкви по заданию сената. Делалось это для проверки полученных данных после ревизий. Стоит отметить, что в переписных данных были отмечены лишь лица мужского пола, но несмо- 
тря на это, все же можно приблизительно отследить по дате рождения ребенка время вступления в брак.

Прежде чем приступить к рассмотрению средней продолжительности жизни на территории Мордовского края во второй половине XVIII века стоит рассмотреть источники того времени. Для данного исследования была использована «Книга переписная разночинцев, однодворцев, дворовых крестьян г. Красная слобода, дворцовых (русские, мордва) крестьян и однодворцев Краснослободского уезда». Как было отмечено выше, данную работу проводил Синод для проверки подлинности данных II ревизии.

Теперь стоит подробно остановится на документе. Так по итогам II ревизии в уезде насчитывалось 4962 души мужского пола, из которых в связи с ветхостью документа были получены данные о 4944 душе, которые относились к 2844 семьям.

Ниже приведена гистограмма 1 податного населения мужского пола по возрастам г. Красная слобода и Краснослободского уезда за 1745 г. Так, согласно данной гистограмме, средний возраст населения в Краснослободском уезде составлял - 26,24 года.

Переходя непосредственно к рассмотрение повозрастной динамики податного населения стоит отметить, что возраст детей до 1 года не приравнивалась к 1. Так в 1745 г. повозрастная картина мужского населения была следующая:

— от 0 до 15 было 1564 чел.;

- от 15 до 30 - 1431 чел.;

— от 30 до 45 - 1128 чел.;
— от 45 до 60 - $\mathbf{5 7 0}$ чел.;

— от 60 до 90 - 249 чел.;

— от 90 и выше - 2 чел.

Средний возраст мужского населения равнялся:

- от 0 до 15 составила- 4,8 года;

— от 15 до 30 - 19,96 года;

— от 30 до 45 - 35,7 года;

— от 45 до 60 - 49,78 года;

— от 60 до 90 - 67,8 года;

— от 90 и выше - 90,9 года.

Полученные данные показывают, что самая большая доля мужчин относится к категории до 15 лет - 1564 души или 31,6\% (диаграмма 1.), далее идут от 15 до $30-1431$ души или 28,94\%, от 30 до 45 - 1128 душ или 22,82\%, от 45 до 60 - 570 души или 11,53\%, от 60 до 90 - 249 душ или 5,07\%, 90 и более - 29 или около 0,04\%.

Чтобы более подробно рассмотреть динамику продолжительности жизни стоит изучить таблицу 1. и график 1. Полученные данные показали следующее половозрастное деление:

1. от 1 до 5 - 614 чел., что составляло 12,42\% от всего населения;

2. от 6 до 12 - 793 чел., что составляло $16,04 \%$ от всего населения;

3. от 13 до 19 - 618 чел., что составляло $12,5 \%$ от всего населения;

4. от 20 до 29 - 970 чел., что составляло 19,62\% от всего населения;

5. от 30 до 39 - 765 чел., что составляло 15,47\% от всего населения;

6. от 40 до 49 - 593 чел., что составляло $12,00 \%$ от

Гистограмма 1.

Повозрастное податное мужское население г. Красная слобода и Краснослободского уезда за 1745 г.

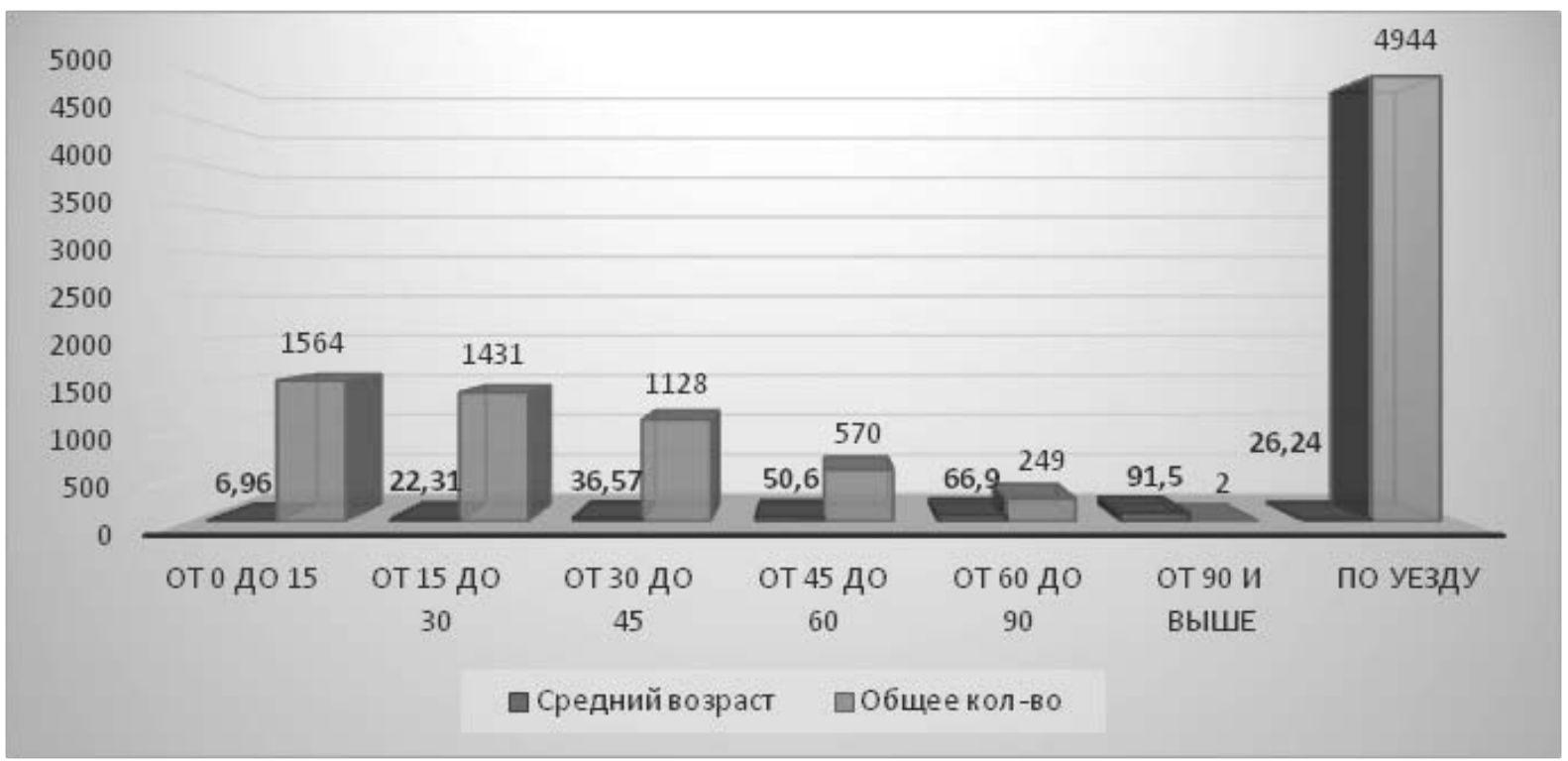


Диаграмма 1.

Повозрастное податное мужское население г. Красная слобода и Краснослободского уезда за 1745 г.

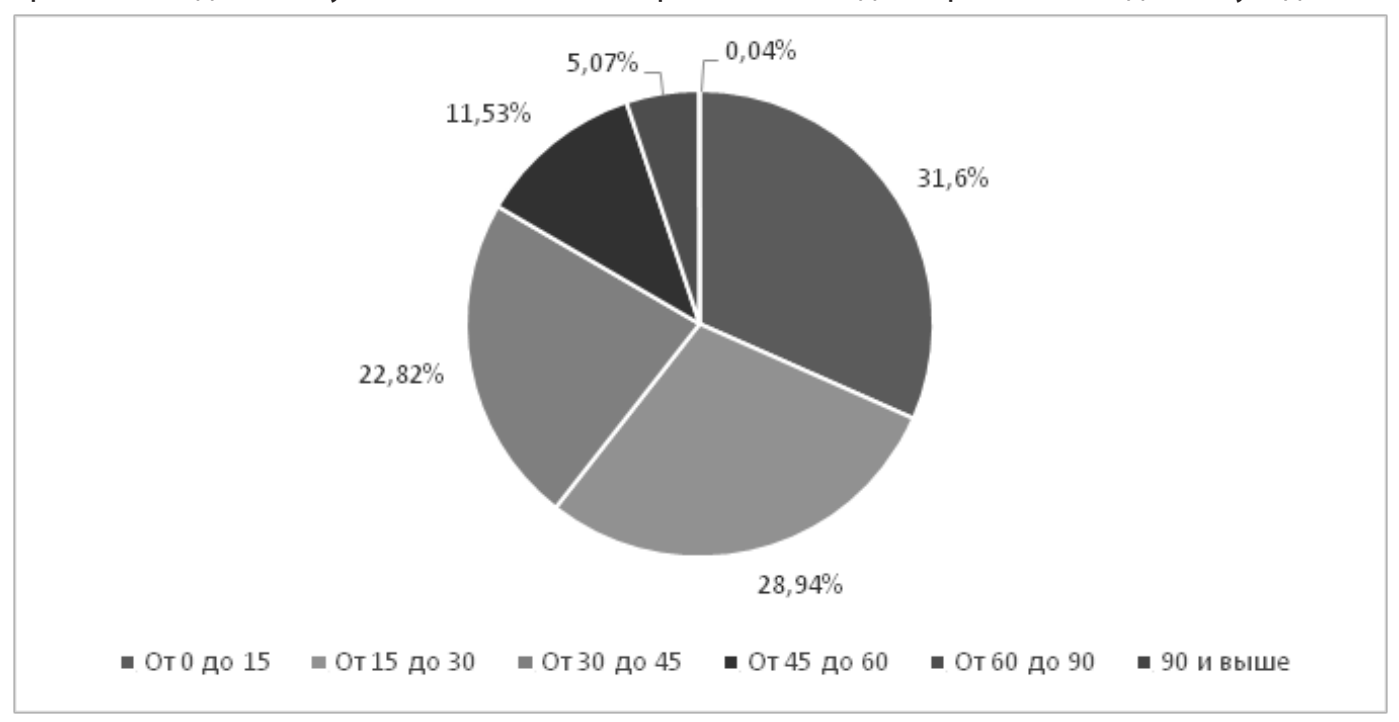

Таблица 1.

Повозрастная численность мужского населения г. Красная слобода и Краснослободского уезда за 1745 г.*

\begin{tabular}{|c|c|c|}
\hline \multirow{2}{*}{ Возраст } & \multicolumn{2}{|c|}{ Число душ } \\
\cline { 2 - 3 } & абс. & в \% к итогу \\
\hline $6-5$ & 614 & 12,42 \\
\hline $6-12$ & 793 & 16,04 \\
\hline $13-19$ & 618 & 12,5 \\
\hline $20-29$ & 970 & 19,62 \\
\hline $30-39$ & 765 & 15,47 \\
\hline $40-49$ & 593 & 12 \\
\hline $50-59$ & 340 & 6,88 \\
\hline $60-69$ & 169 & 3,42 \\
\hline $70-79$ & 67 & 1,35 \\
\hline $80-89$ & 13 & 0,26 \\
\hline 90 и более & 2 & 0,04 \\
\hline Всего & 4944 & $100 \%$ \\
\hline
\end{tabular}

* Статистика того времени не знала «нулевого» возраста: младенцы до 1 года, фиксировались группе годовалых детей

всего населения;

7. от 50 до 59 - 340 чел., что составляло $6,88 \%$ от всего населения;

8. от 60 до 69 - 169 чел., что составляло 3,42\% от всего населения;

9. от 70 до 79 - 67 чел., что составляло 1,39\% от всего населения;

10. от 80 до 89 - 13 чел., что составляло $0,26 \%$ от всего населения;

11. в возрасте 90 и более - 2 чел., что составляло 0,04\% всего населения.
Полученные данные показали, что самое большое число душ числилось в возрасте от 20 до 29 лет. Также стоит отметить и большую численность подростков: в возрасте от 6 до 12 лет числилось 793 мужчины.

Далее с помощью гистограммы 2 и графика 2 был рассмотрена средний возраст мужчин в 3 категориях:

- Мужчины до 18 лет;

- Мужчины старше 18 лет;

- Средний возраст по Уезду.

Как видно из представленных данных мужчин в воз- 
График 1.

Количество и возраст жителей г. Красная слобода и Краснослободского уезда за 1745 г.

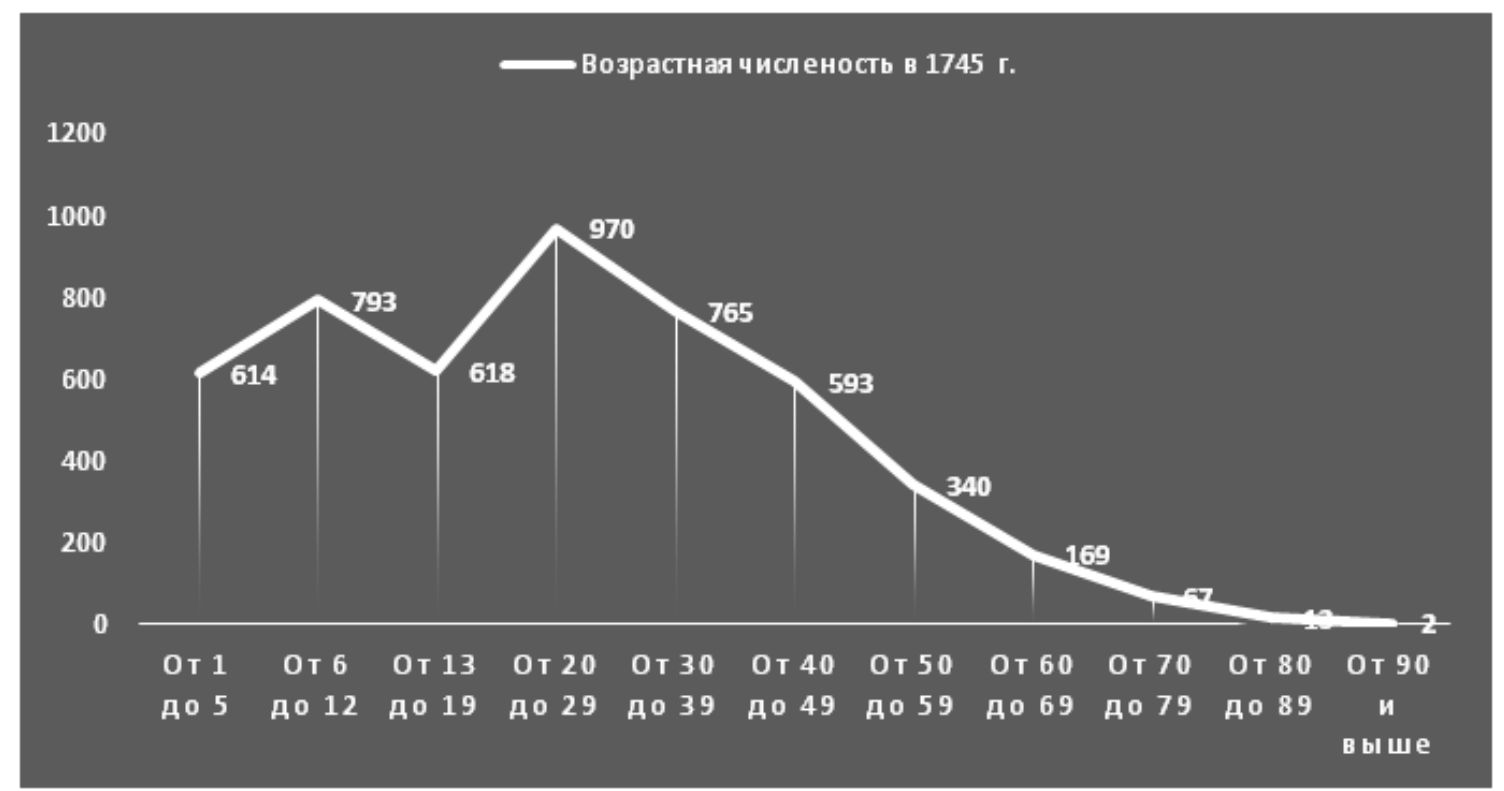

Гистограмма 2.

Количество населения и средний возраст детей и взрослых г. Красная слобода и Краснослободского уезда за 1745 г.

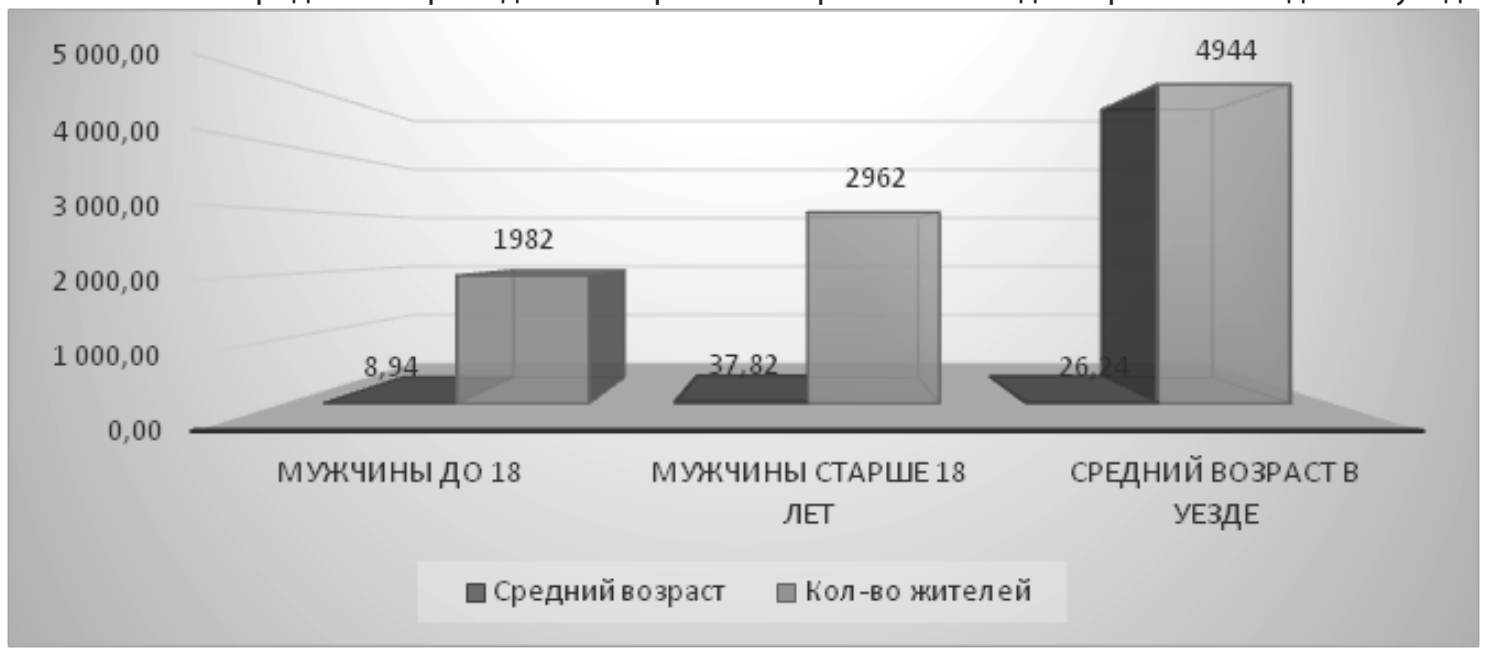

Количество детей и взрослых г. Красная слобода и Краснослободского уезда за 1745 г.

График 2.

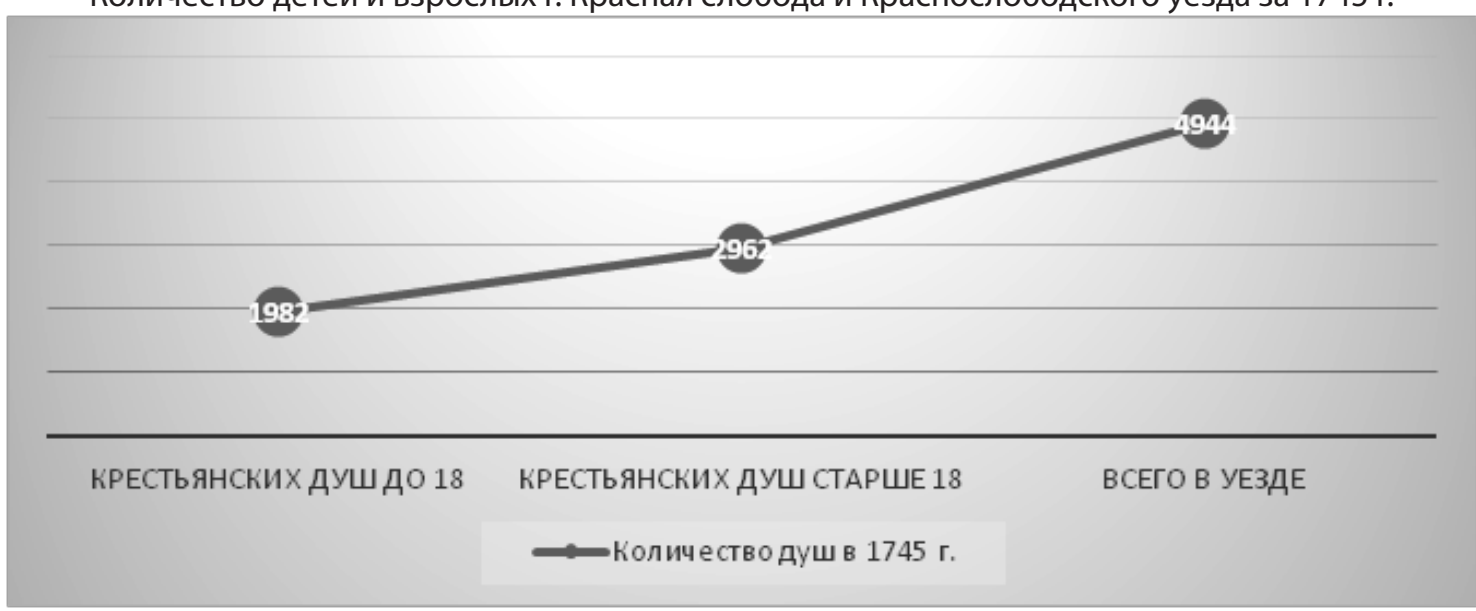


Количество и средний возраст детей (достигшие зрелости) и взрослых г. Красная слобода и Краснослободского уезда за 1745 г.

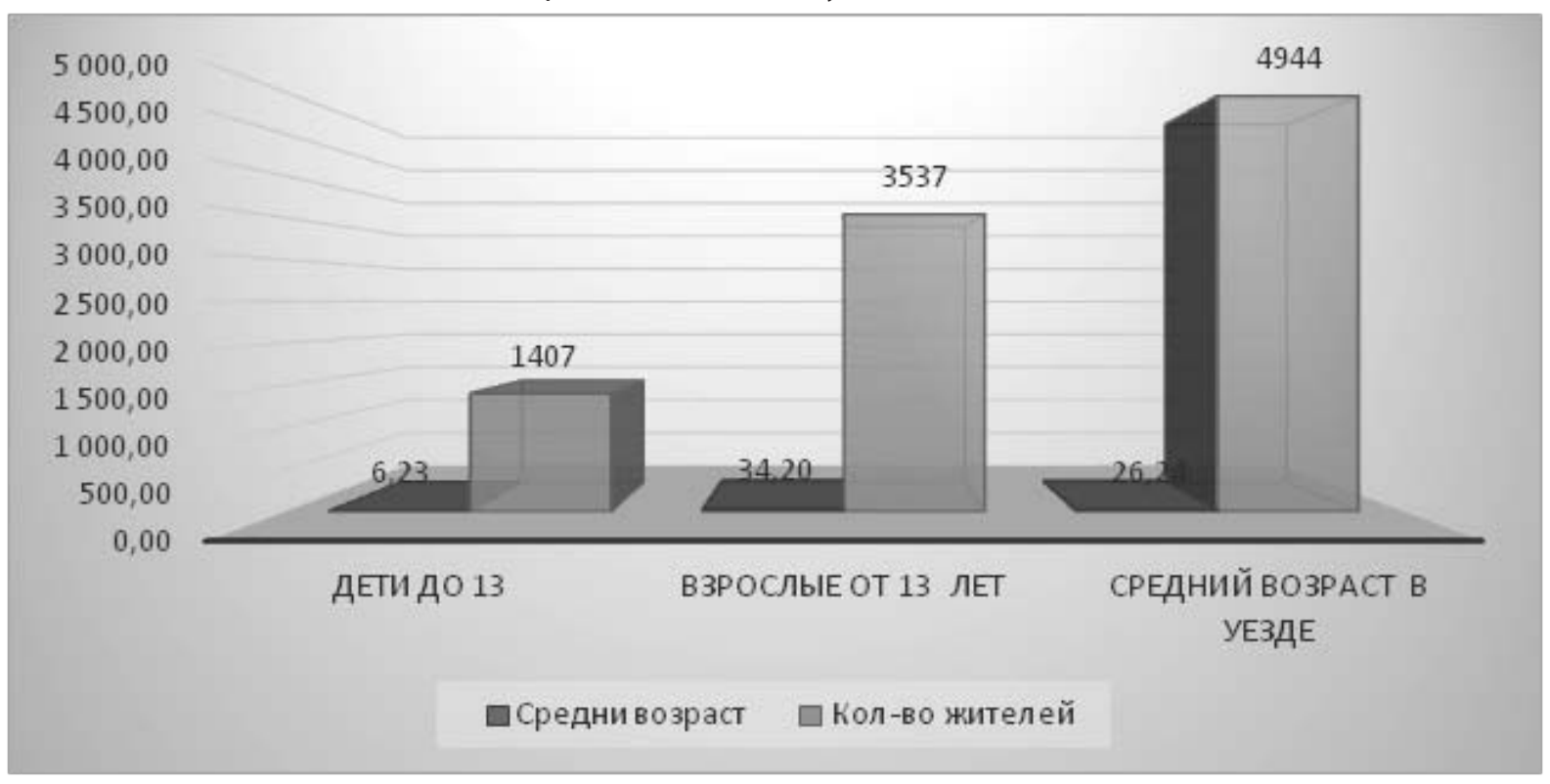

расте до 18 лет числилось - 1982 чел. Средний возраст составил - 8,94 года. Мужчин старше 18 лет - 2962 чел. Средний возраст равнялся - 37,82 года. В целом по уезду средний возраст составил 26,24 года, что являлось приближенным значением не только на территории Республики Мордовии, но и в целом по России.

Стоит отметить, что большинство советских и современных исследователей считают, что возраст зрелости достигал уже с 13 лет, поэтому было решено рассмотреть данную концепцию более наглядно в гистограмме 3. Так, например, мужчин в возрасте до 13 лет числилось 1407 чел., где средний возраст составил - 6,23 года. Мужчин старше 13 лет - 3537 чел., где средний возраст составил - 34,20 года. Полученные данные показали, что в отличие от гистограммы 2, данные существенно уменьшились, как среди детского, так взрослого населения.
В заключение стоит отметить, что в начале второй половины XVIII века на территории современной Республики Мордовия средняя продолжительность жизни составила - 26,24 года, что было приближено к показателям, которые были показаны в целом на территории Российской империи. Конечно, стоит отметить, что при рассмотрение мужского населения старше 18 лет, средний возраст увеличится уже до 37,82 года.

Была отмечено, что лиц, не достигших 18 лет - было чуть больше $40 \%$.

Данная тенденция не могла не повлиять на тенденцию развития крестьянской семьи и крестьянского домохозяйства, так как чуть более $40 \%$ лиц мужского пола могло достигнуть трудовой зрелости и тем сам продолжить развитие не только своего хозяйства, но и страны в целом.

\section{ЛИТЕРАТУРА}

1. Российский государственный архив древних актов (РГАДА) - Ф-350. Книга переписная разночинцев, однодворцев, дворовых крестьян Воронежской губернии Шацкой провинции г. Красная слобода и Краснослободского у. 1745 г. Оп. 1, д. 1594. 